\title{
EGU2020-10701
}

https://doi.org/10.5194/egusphere-egu2020-10701

EGU General Assembly 2020

(c) Author(s) 2020. This work is distributed under

the Creative Commons Attribution 4.0 License.

\section{Towards a neural network approach for automated recognition of lichen-covered prehistoric carvings at Stonehenge}

Gavin Leong and Matthew Brolly

University of Brighton, School of Environment and Technology, United Kingdom of Great Britain and Northern Ireland (g.leong@brighton.ac.uk)

Petroglyphs (rock carvings) are a form of tangible cultural heritage that have been used to investigate cultural change and understand the origins of art and belief. However, many sites with rock carvings are accompanied by lichen. They often obscure these panels of rock art, rendering the cultural artefacts inaccessible to study, documentation and public enjoyment. Above all, lichencovered rock carving is under the threat of lichen-attributed physical and chemical erosion. But evidence of a simultaneous protective role played by lichen has prompted concern that the removal of lichen may result in more rapid deterioration of the rock art.

Stonehenge, a UNESCO World Heritage site, provides a strong case study as dense lichen covers roughly a quarter of its above-ground stone surfaces, rendering it inaccessible to examination. 72 Early Bronze Age carvings have recently been found on the bare stone surfaces prompting concerns that lichen may be obscuring prehistoric rock art.

As a first step towards creating a technique for revealing carvings beneath lichen, an interdisciplinary approach was implemented. Photogrammetry-derived 3-D modelling and machine learning code written in Python were combined to create a method for identifying repeating carving motifs on bare stone surfaces. This code, a neural network classifier called MeshNet, "learns" 3-D shape representation from mesh-based 3-D models and was adapted to capture features of the rock carvings. After training on 150 models (75 carving and non-carving areas of the rock surface each) and testing on 38 models (19 carvings and non-carvings each), our method achieved $84.2 \%$ accuracy.

In previous work, we have shown that it is possible to recover indications of carvings covered by digitally simulated lichen. Thus, it will be possible to repeat our method on the same carvings with coverage of simulated lichen to compare accuracies. If successful, it will be the first demonstration of a technique capable of revealing carvings obscured by lichen using only a surface imaging technique.

Our current methodology for identifying rock carvings can be adopted by conservators and rock art site managers. It serves as a tool for non-rock art specialists to discover and digitally record repeating rock carving motifs. With further development using simulated lichen, it will partially alleviate the need to remove lichen from panels of rock carvings. 
As our method is scale invariant, it could also be adapted for use in airborne and UAV platforms for discovering e.g. repeating natural landforms hidden by forest cover and buried Roman roads in 3-D terrain maps. 